\title{
Trends in Mortality Due to Ischemic Heart Disease in the Municipality of Goiania, Brazil, during the Years between 1980 and 1994
}

\author{
Suzana Alves de Moraes, Márcia Helena Vieira de Rezende, Isabel Cristina Martins de Freitas
}

Ribeirão Preto, SP - Brazil

\begin{abstract}
Objective - To analyze the trends of specific, standardized coefficients of mortality due to ischemic heart disease according to sex and age during the years 1980 and 1994 in the municipality of Goiania, GO, Brazil.
\end{abstract}

Methods - Data on deaths were retrieved from the Information on Mortality System of the Ministry of Health; population data were obtained from the Foundation of the Brazilian Institute for Geography and Statistics (IBGE). The trends of the specific coefficients were analyzed by triennia of the historical series, including individuals of both sexes from 25 years of age on, partitioned into 6 age groups of ten years intervals. The population data corresponding to the year 1980 were used as the standard for the calculation of each age group coefficient. Analyses were carried out by straight linear regression.

Results - Coefficients were greater for males in each triennium of the series and increased with age in both sexes. The study of the trends of the specific age coefficients of both sexes revealed a stable pattern of evolution up to the age of 65-74 years $(P>0.05)$. From 75 years on, a clearcut decline in mortality due to ischemic heart disease was shown by both sexes. The standardized coefficients also showed a significant decline ( $p \leq 0.05)$.

Conclusion - The municipality of Goiânia is at present in a stage of epidemiological transition similar to that of developed countries, even though the observed decline is predominantly influenced by the mortality of older individuals ( 75 years of age or older).

Keywords: mortality, myocardial ischemia, trend studies

Escola de Enfermagem de Ribeirão Preto - USP

Mailing address: Suzana Alves de Moraes - Av. Santa Luzia 440/81 - 14025-090Ribeirão Preto, SP - Brazil
Ischemic heart disease results in high mortality rates; since the beginning of the second half of the $20^{\text {th }}$ century, it has stood out as one of the major causes of death in the majority of developed and developing countries.

Yet, during the last 40 years, after a practically stationary period, the trend of these rates has been to decline in the US, Canada, Australia, Japan, the United Kingdom and other West European countries ${ }^{1}$.

In Brazil, the trend towards a decline in mortality due to ischemic heart disease was first recognized in the municipality and state of São Paulo at the end of the nineteen seventies $^{2-4}$. Between 1979 and 1989, this decline was also reported in other Brazilian capitals like Salvador, Belém, Belo Horizonte and Curitiba ${ }^{4,5}$.

Considering the existence of regional differences in Brazil, it can be intuitively concluded that not all of these regions are going through the $4^{\text {th }}$ stage of epidemiological transition, which, according to Onram ${ }^{6}$, is characterized by trends towards a decline in cardiovascular disease.

With this perspective in mind, we proposed to identify the transitional characteristics of the trends in mortality caused by ischemic heart disease in the historic period falling between 1980 and 1994 in Goiânia, a metropolitan capital located in midwestern Brazil.

\section{Methods}

The study is classified as the ecological picture of a historical series type. ${ }^{7}$

Information on deaths of residents of Goiânia was retrieved from the CD-Rom-1996: Mortality Information System (SIM $)^{8}$ distributed by DATASUS-CENEPI-FNS of the Health Ministry. Data that were not yet definitive (1993 and 1994), were updated directly by DATASUS-CENEPI ${ }^{9}$. Deaths were considered of interest when classified between codes 410 and 414.9 of the International Disease Classification CIDRevision $\mathrm{IX}^{10}$. Population data for the period under study were collected from the Fundação Instituto de Geo- 
grafia Estatística (FIBGE) $)^{11,12}$ - Goiás Sector, in Goiânia; population estimates for intercensus years of the period were calculated by interpolation according to Arriaga, using the Population Analysis with Spreadsheet (PAS) Program ${ }^{13}$.

According to the proposal of the FIBGE ${ }^{11,12}$, individuals between 25 and 75 years or over; were grouped in age intervals of ten years.

Specific coefficients of mortality were calculated by sex and age group for each triennium of the historic series studied; general coefficients standardized by age and sex were calculated using the age structure of the population of the 1980 census as standards ${ }^{14}$.

Databanks with information about the deaths of residents of Goiânia between 1980 and 1994 arranged according to basic causes between 1980 and 1994 were retrieved from the Mortality Information System (SIM) ${ }^{8}$ tested using Foxpro version 2.6 software ${ }^{15}$ by routines for recodification and creation of new variables of interest for the study as follows: sex, age, year of death and death by ischemic heart disease. Electronic mapping was developed for the calculation of specific and standardized coefficients using Excel version 7.0 software ${ }^{16}$.

Deaths by ischemic heart disease were classified according to sex and age using Epiinfo version $6.04 \mathrm{c}$ software ${ }^{17}$. This information was fed into electronic mappings developed with Excel version 7.0 software. For tendency analyses, straight linear regressions were used; hypotheses were tested using a significance level $\alpha=0.05$; processing was done with the SPSS program for Windows version $7.0^{18}$.

\section{Results}

Mortality indicators for ischemic heart disease were applied to individuals from 25 years of age on because no deaths from this cause were found in younger age groups.

To minimize possible bias related to the International Disease Classification, the work was conducted using the historical series during which only IX Revision ${ }^{10}$ was in effect.

Table I shows specific mortality coefficients of ischemic heart disease according to sex and age as well as general standardized coefficients according to sex for each triennium.

Figures 1 to 6 depict the tendencies of specific mortality coefficients in the historic series between 1980 and 1994 for each of the age groups studied according to sex. Figure 7 shows the tendency of standardized coefficients by age and sex.

\section{Discussion}

The results presented in table I allowed us to conclude that in each triennium the size of the coefficients was greater for males and increased with aging in both sexes. From 65 years onwards, the size of the coefficients for females tended to fall closer to those of males; these findings have been corroborated by various authors ${ }^{2-5}$.

The trends of the specific coefficients of the historical series studied (figs. 1 to 6) illustrate a specific situation of epidemiological transition for the municipality of Goiânia. According to this trend, it was possible to identify significant declines in the coefficients in both sexes, but only from 75 years of age onwards $(\mathrm{P}<0.05)$. It should be noted that in age

\begin{tabular}{|c|c|c|c|c|c|c|}
\hline \multirow[b]{2}{*}{ Age } & \multirow[b]{2}{*}{ Sex } & \multicolumn{5}{|c|}{ Specific coefficients/100.000 individuals/year } \\
\hline & & 80 a 82 & 83 a 85 & 86 a 88 & 89 a 91 & 92 a 94 \\
\hline \multirow[t]{3}{*}{$25-34$} & $\mathrm{M}$ & 1.7863 & 8.0432 & 5.3454 & 4.4999 & 3.3153 \\
\hline & $\mathrm{F}$ & 1.1055 & 1.9587 & 1.7459 & 2.3777 & 0.7224 \\
\hline & $\mathrm{T}$ & 1.4332 & 4.8629 & 3.4491 & 3.3715 & 1.9299 \\
\hline \multirow{3}{*}{$35-44$} & M & 16.9324 & 25.7599 & 15.4788 & 21.3227 & 22.5916 \\
\hline & $\mathrm{F}$ & 6.3291 & 10.9420 & 4.7450 & 8.3596 & 7.3146 \\
\hline & $\mathrm{T}$ & 11.5257 & 18.1240 & 9.8872 & 14.4860 & 14.4605 \\
\hline \multirow[t]{3}{*}{$45-54$} & $\mathrm{M}$ & 70.6745 & 89.3444 & 77.8045 & 73.2246 & 82.0614 \\
\hline & $\mathrm{F}$ & 25.4626 & 36.2550 & 18.8769 & 26.0589 & 32.7840 \\
\hline & $\mathrm{T}$ & 47.6160 & 62.1401 & 47.4598 & 48.7959 & 56.3664 \\
\hline \multirow[t]{3}{*}{$55-64$} & $\mathrm{M}$ & 207.1070 & 228.8493 & 224.0791 & 236.3268 & 196.3917 \\
\hline & $\mathrm{F}$ & 104.5466 & 77.8718 & 82.3904 & 88.9061 & 92.6441 \\
\hline & $\mathrm{T}$ & 152.9052 & 148.6648 & 148.4825 & 157.1467 & 140.5044 \\
\hline \multirow[t]{3}{*}{$65-74$} & M & 495.7240 & 432.9630 & 445.2440 & 423.9100 & 448.5390 \\
\hline & $\mathrm{F}$ & 350.3220 & 242.7680 & 241.4690 & 205.0330 & 196.3950 \\
\hline & $\mathrm{T}$ & 418.4210 & 330.4500 & 333.8570 & 302.2300 & 306.8640 \\
\hline \multirow[t]{3}{*}{$75 \mathrm{e}+$} & M & 1562.2257 & 1296.6878 & 1288.5724 & 909.8428 & 935.7784 \\
\hline & $\mathrm{F}$ & 1423.3066 & 1137.4116 & 812.4016 & 623.5597 & 727.6565 \\
\hline & $\mathrm{T}$ & 1481.6453 & 1204.4618 & 1013.8690 & 745.0751 & 815.8956 \\
\hline Standardized & M & 80.7653 & 84.1965 & 78.4278 & 73.6156 & 72.8016 \\
\hline \multirow[t]{2}{*}{ Coefficients } & $\mathrm{F}$ & 59.1727 & 49.5045 & 39.4118 & 37.1796 & 39.1610 \\
\hline & $\mathrm{T}$ & 69.5884 & 66.0957 & 57.9665 & 54.2854 & 54.7539 \\
\hline
\end{tabular}




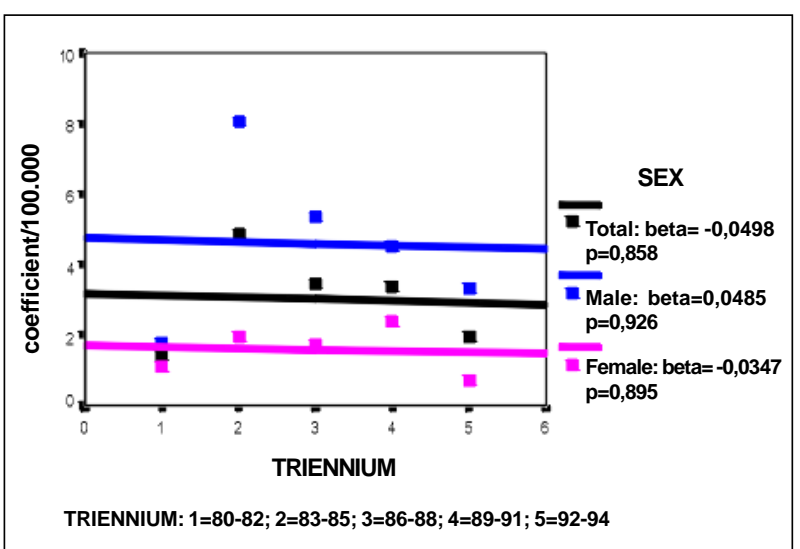

Fig.1 - Tendency of specific coefficients according to sex. Age group 25-34 years in 5 Triennia.

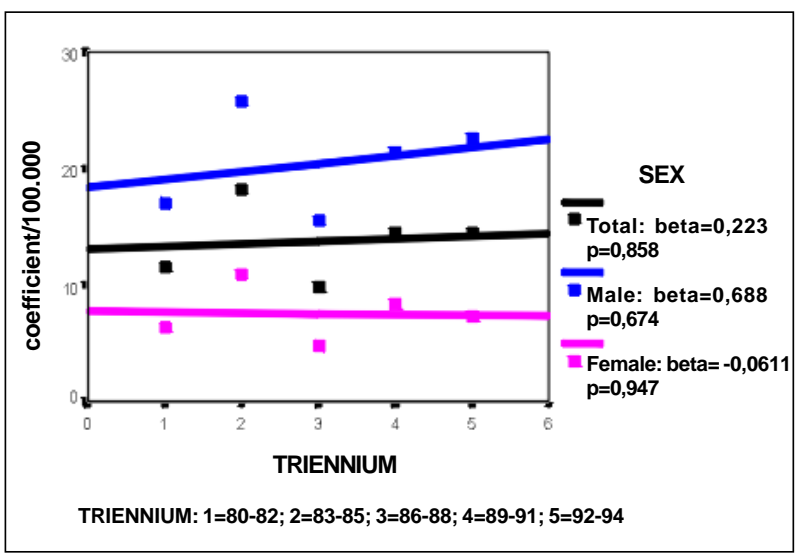

Fig.2 - Tendency of specific coefficients according to sex. Age group 35-44 years in 5 Triennia.

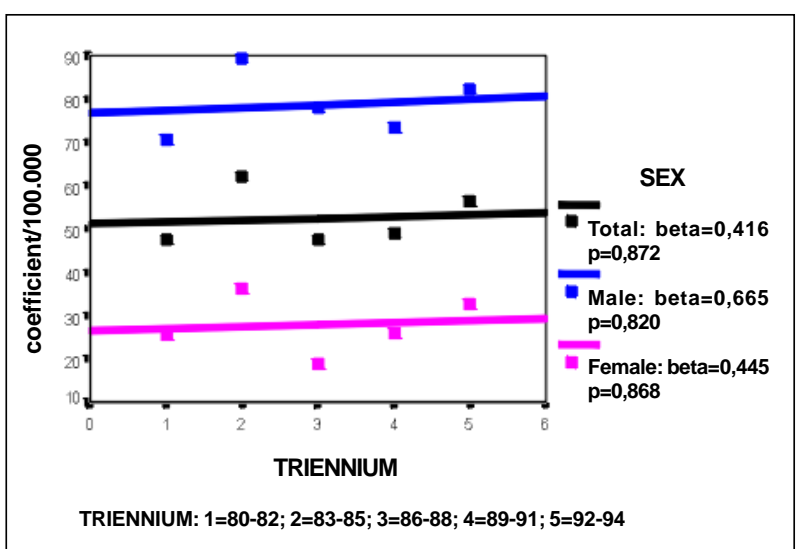

Fig.3 - Tendency of specific coefficients according to sex. Age group 45-54 years in 5 Triennia.

ranges below 75 years, the trend was for these coefficients to remain stable during the period, a significant decline for the 65-74 age group only being noticed in females $(\mathrm{P}<0.05)$.

Analysis of the trends of standardized coefficients (fig.7) showed a significant decline for both sexes $(\mathrm{P}<0.05)$ over the period.

Lolio et al. ${ }^{3}$ studying the trends of standardized

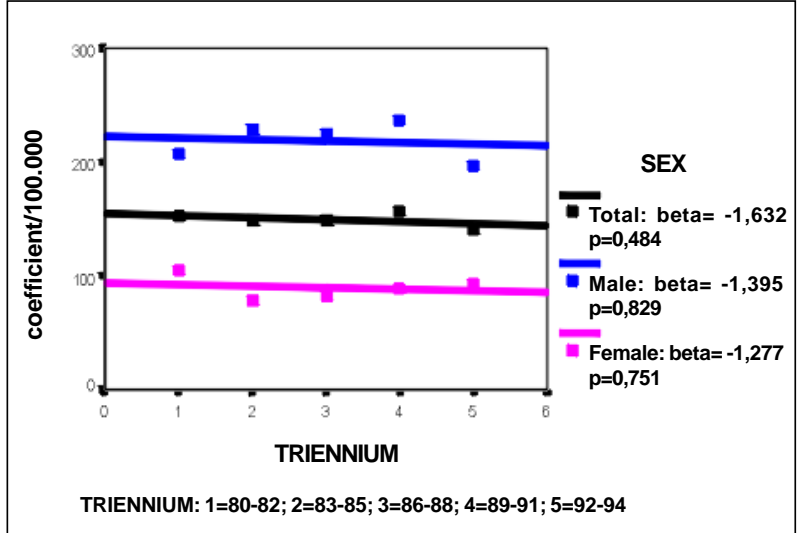

Fig.4 - Tendency of specific coefficients according to sex. Age group 55-64 years in 5 Triennia.

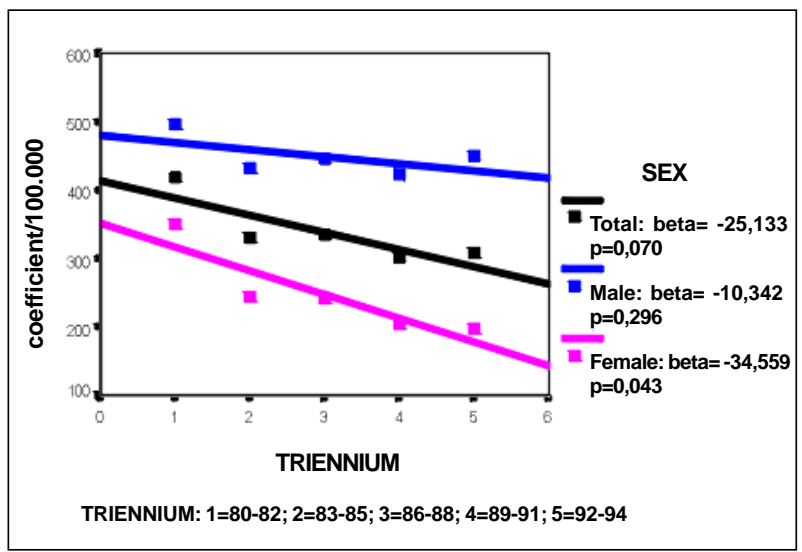

Fig.5 - Tendency of specific coefficients according to sex. Age group 65-74 years in 5 Triennia.

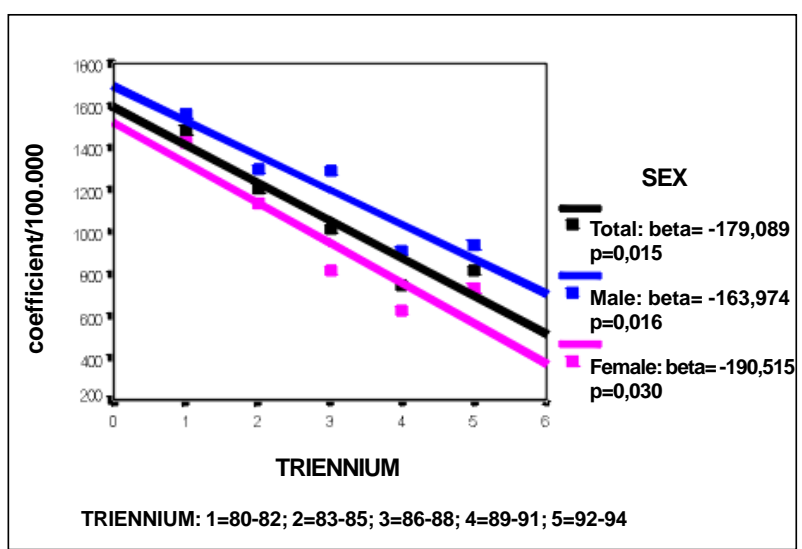

Fig.6 - Tendency of standardized coefficients according to sex. Age group 75 years and $(+)$ in 5 Triennia.

coefficients of mortality due to ischemic heart disease in the municipality of São Paulo between 1970 and 1983 detected a significant decline in the specific coefficients from 50 years of age onwards in both sexes.

The findings regarding the trends of standardized coefficients in the present study-agree with those of Lolio et al. ${ }^{5}$ for the municipalities of São Paulo, Belém and Belo Hori- 


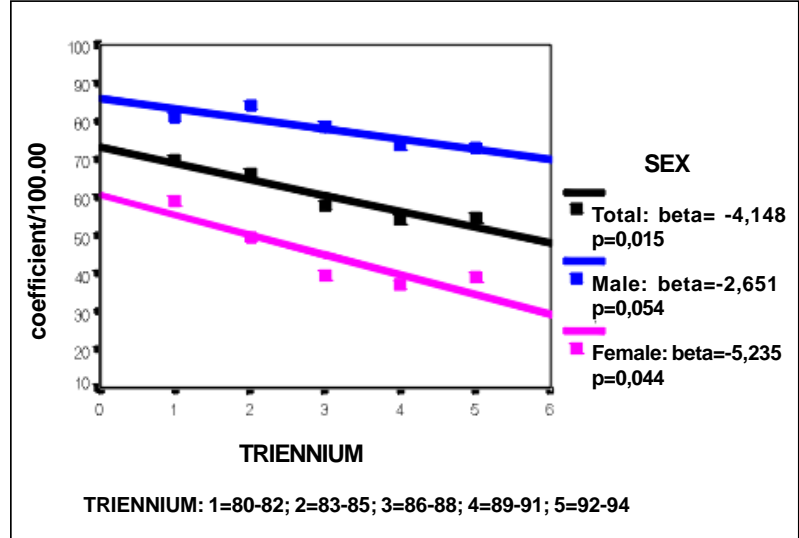

Fig.7 - Tendency of specific coefficients according to sex Age group 75 years and (+) in 5 Triennia.

zonte during the period between 1979 and 1989. Similar results have been reported by other authors: Sá et al. ${ }^{19}$ in Portugal in the eighties, Osler et al. ${ }^{20}$ in Denmark from 1982 to 1992, Salomaa et al. ${ }^{21}$ in Finland between 1983 and 1988 and Beaglehole et al. ${ }^{22}$ in New Zealand between 1983 and 1993.

Various authors have recognized the contribution of medical assistance and primary prevention measures as variables capable of explaining the observed decline in mortality ${ }^{23,24}$. Goldman and Cook $^{24}$ detected a $60 \%$ decline in mortality due to ischemic heart disease in the United States between 1968 and 1976 related to changed life styles, in particular, reduction in serum cholesterol levels and control of smoking; a $40 \%$ decrease was attributed to specific medical interventions in these cases.

Although several studies have been made in Brazil, the participation of factors responsible for the decline in mortality due to ischemic heart disease is not precisely known. Absence of studies of historical series, of protection from or incidence of risk factors, as well as of analytical studies aimed at testing their association with mortality have as yet offered limited desirable explanations for the observed decline in the incidence of the disease.

In the case of Goiânia, however, the improved quality of more complex medical assistance (coronary care units, angioplasty and myocardial revascularization) rather than a desirable decrease in risk factors may have contributed to the decreased mortality ${ }^{4}$ in individuals with greater risk of having fatal complications (higher age groups) and may perhaps be a better explanation for the observed decline. Because ischemic heart disease has a long latency period, programs for intervention on risk factors do not appear to have influenced incidence and mortality in younger segments of this population.

Concerning recommendations for the standardization of these coefficients for the study of mortality trends during periods when extreme modifications of respective age pyramids are observed, it is worth noting that the significant decline in these standardized coefficients is mainly due to the contribution of older age groups, as clearly evidenced by the evolution of the specific coefficients of this population (figs. 1 to 6).
An important factor related to the quality of the information collected when performing mortality studies on historical series is the percentage of ill-defined causes, classified in chapter XVI of the CID-IX Revision ${ }^{10}$. Lolio ${ }^{25}$ recommends that the proportion of ill-defined causes should not run over $10 \%$. Records from the midwestern region of Brazil show more than $10 \%$ of deaths are of the ill-defined group; we therefore decided to perform a study of the proportional tendency towards mortality due to ill-defined causes in individuals older than 25 years in Goiânia for the historical period between 1980 and $1994{ }^{26}$. Figure 8 indicates the results of this trend: the average values expressed by the adjusted straight line varied between 16 and $10 \%$ for the beginning and the end of the period studied, respectively, showing a significant decline for this group of causes $(\mathrm{p}<0.05)$. These findings speak in favor of a real decline in mortality due to ischemic heart disease. Standardized coefficients presented in figure 7 suggest that the decline in the percentages of ill-defined causes over the period must have occurred due to notifications of deaths from causes other than ischemic heart disease. It is also worth pointing out that the distribution of the percentages of ill-defined causes was not concentrated in specific age bands over the historical series studied. This appears to validate the results related to the pattern of evolution of mortality by ischemic heart disease in specified age groups shown in figures 1 to 6 .

Descriptive mortality studies are recognized as important sources for the planning and evaluation of health services at all levels of assistance. It is known that they generate explanatory hypotheses of causal determinants for interventions in individual and collective health. For example, Laurenti ( $2^{\text {nd }}$ National Meeting of the Sub-System of Mortality Information-Brasília, 1987 reports that the use of statistical mortality data enabled knowledge acquisition about trends towards the decline in mortality coefficients due to ischemic heart disease following a period of increase in industrialized countries. It consequently generated the need to evaluate the effect of interventions on aggravating risk factors.

Despite some limitations related to mortality due to basic causes, the trend observed in the Goiânia municipality between 1980 and 1994 seems to indicate an epidemiological

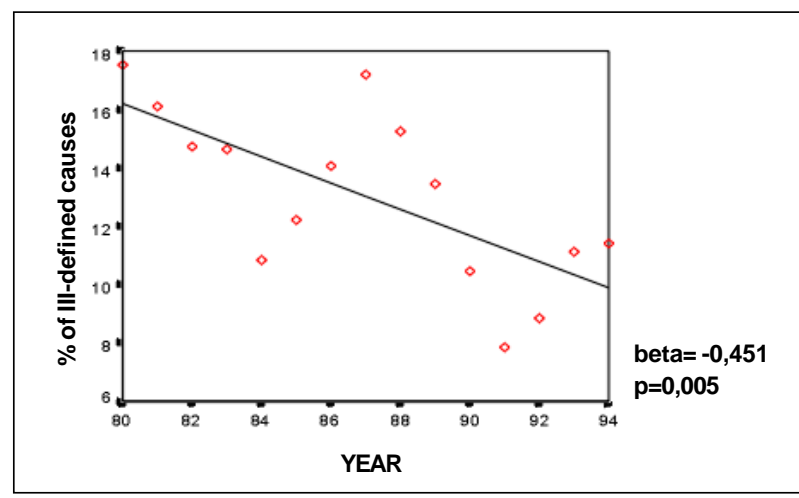

Fig.8 - Proportional mortality due to III-defined causes adults 25 years and older. Goiânia 1980-1994. 
transition pattern similar to that of developed regions $\left(4^{\text {th }}\right.$ period of epidemiological transition ${ }^{6}$ ), even though the decline in mortality due to this group of causes is predominantly occurring in individuals 75 years or older.

It is hoped that the results pointed out by this study may stimulate the development of epidemiological research aimed at developing analytical designs for the testing of hypotheses to explain the specific determinants of local transition to subsidize the -establishment-of programs to prevent and control these aggravating factors.

\section{References}

1. Beaglehole R. International trends in coronary heart disease mortality, morbidity, and risk factors. Epidemiologic Reviews 1990; 12: 1-15.

2. Lólio CA, Laurenti R. Mortalidade por doença isquêmica do coração no Município de São Paulo. Evolução de 1950 a 1981 e mudanças recentes na tendência. Arq Bras Cardiol 1986; 46: 153-6.

3. Lólio CA, Souza JMP, Laurenti R. Decline in cardiovascular disease mortality in the city of São Paulo, Brasil, 1970 to 1983. Rev Saúde Pública 1986; 20: 454-64.

4. Lotufo PA, Lolio CA. Tendência da mortalidade por doença isquêmica do coração no Estado de São Paulo: 1970-1989. Arq Brasil Cardiol 1993; 61: 149-53.

5. Lólio CA de, Lotufo PA, Lira AC,Zaneta DMT, Massad E. Tendência da mortalidade por doença isquêmica do coração nas capitais de regiões metropolitanas do Brasil, 1979 - 1989. Arq Brasil Cardiol 1995; 64:195-9.

6. Omram AR. The Epidemiologic Transition in the Americas. Washington, PAHOThe University of Maryland at College Park, 1996.

7. Hennekens CH, Buring JE. Epidemiology. In: Medicine. Boston: Little Brown and Co, 1987.

8. Brasil, Ministério da Saúde. DATASUS - CENEPI. Sistema de informação sobre mortalidade -CD-ROM. Brasília, maio, 1996.

9. Brasil, Ministério da Saúde. Mortalidade Brasil, 1995, Brasília, Coordenação de Comunicação, Educação e Documentação, 1996: 553p.

10. Organização Mundial da Saúde. Manual de Classificação Estatística Internacional de Doenças, Lesões e Causas de Óbitos, $9^{\mathrm{a}}$ Revisão, 1975. São Paulo, Centro da OMS para Classificação de Doenças em Português/Ministério da Saúde/Universidade de São Paulo/Organização Pan Americana da Saúde, 1985, vol.1.

11. Fundação Instituto Brasileiro de Geografia e Estatística. Censo demográfico: Goiás. Rio de Janeiro, 1994. (10 Recenseamento Geral do Brasil, 1991).

12. Fundação Instituto Brasileiro de Geografia e Estatística. Censo demográfico: Goiás. Rio de Janeiro, 1982. ( $9^{\circ}$ Recenseamento Geral do Brasil, 1980).

13. Arriaga EE. Population Analysis with Microcomputers. New York: New York University Press. Vol I e II. November, 1993.
14. Laurenti R, Mello Jorge MHP, Lebrão ML, Gotlieb SLD. Estatísticas de Saúde. São Paulo, EPU/EDUSP, 1985.

15. Fox Holdings Inc. Foxpro vs.2.6.C/S. [software]Pat.Pend. AmericanEdition, 1991.

16. Microsoft Corporation. Microsoft Excel. 1995 para Windows 95. Excel vs. 7.0 Copyright 1985-1995.

17. Dean J, et al. Epiinfo - computer programs for Epidemiology. Atlanta, Division of Surveillance and Epidemiology Studies, Epidemiology Programs Office, Center for Disease Control, 1997.

18. SPSS-Statistical Package in Social Science: Release 7.0. CopyrightÓ SPSS Inc., 1996.

19. Sá PD, Dias JA, Miguel JMP. Evolução da mortalidade por doença isquêmica cardíaca e doenças cerebro-vasculares em Portugal, na década de 80. Acta Medica Portuguesa 1994; 7: 71-81.

20. Osler M, Sorensen TIA, Sorensen S, et al. Trends in mortality incidence and casefatality of ischaemic heart disease in Denmark, 1982-1992. Int J Epidemiol 1996; 25: $1154-9$.

21. Salomaa V, Arstila M, Kaarsalo E, Ketonen M, Kuulasmaa K. Trends in the incidence and mortality from coronary heart disease in Finland, 1983-1988. Am JEpidemiol 1992; 136: 1303-14.

22. Beaglehole R, Stuwart AW, Jackson R, et al. Decline rates of coronary heart disease in New Zealand-Australia, 1983-1993. Am J Epidemiol 1997; 145: 707-13.

23. Havlik RJ, Feinleib M. Proceedings of the Conference on the Decline in Coronary Heart Disease Mortality Bethesda. National Institute of Health, 1979 (NIH publ 79-1610).

24. Goldman L, Cook EF. The decline in heart disease mortality rates in analysis of the comparative effects of medical intervention and changes in lifestyle. Ann Intern Med 1984; 101: 825-36.

25. Lólio CA. Mortalidade por doenças do aparelho circulatório em capitais de regiões metropolitanas do Brasil, 1979-1989. (Tese Livre Docência), Universidade de São Paulo - São Paulo, 1994.

26. Brasil, Ministério da Saúde. Datasus-CENEPI. Sistema de Informação sobre Mortalidade-CD-ROM. Brasília, julho, 1997. 